\title{
Caim, de José Saramago: um rei provisório de uma bíblia carnavalesca
}

\author{
Cain, by Jose Saramago: a temporary king of a carnivalesque Bible
}

\author{
SAULO GOMES THIMÓTEO \\ Universidade Federal da Fronteira Sul (UFFS). Realeza, PR, Brasil.
}

Ia

\begin{abstract}
Resumo: Existe, nos romances de José Saramago, o elemento central da contínua indagação. Na obra Caim, por exemplo, o autor usa o personagem bíblico do título como fonte de desestabilização para o Deus do Antigo Testamento. A partir de um jogo de duplos, o discurso sagrado é constantemente ressignificado por um enfrentamento racional. E a história bíblica, como uma estrutura simbólica e mitológica, vai sendo problematizada, inserindo-se uma voz opositiva e altamente irônica. Dessa forma, o narrador e seu porta-voz (caim) subvertem o lugar de deus, tornando o romance um espaço carnavalizado em que uma nova leitura da Bíblia se constrói.
\end{abstract}

Palavras-chave: José Saramago; carnavalização; Caim; duplo.

\begin{abstract}
There is, in Jose Saramago's novels, the main element of the incessant inquiry. In Cain, for example, the author uses the biblical character as a source of unsettling to the Old Testament's God. From a game of doubles, the sacred speech is constantly reconstructed by a rational confrontation. And the biblical stories as a symbolic and mythological structure is problematized, by inserting in it an opposed and highly ironic voice. Thus, the narrator and his spokesman (cain) subvert god's place, making the novel a carnivalized space in which a new reading of the Bible is built.
\end{abstract}

Keywords: Jose Saramago; carnivalization; Cain; double.

"Um homem que se propõe construir a si mesmo está assumindo o papel do Criador, segundo uma determinada maneira de ver as coisas."

SALMAN RUSHDIE (Os versos satânicos)

A esfera do sagrado, na obra de José Saramago, encontra-se constantemente pautada pelo questionamento dos dogmas e das verdades inquestionáveis. $\mathrm{O}$ narrador e as personagens postos em interação tornam-se uma forma de reflexo ativo de uma doutrina dada (para não dizer imposta), isso força-a a explicar-se ou, pelo menos, a exibir a outra face de si. Por isso que, indo além dos sentidos tradicionais, Saramago subverte a leitura do sagrado para melhor entendê-lo. Em In Nomine Dei, mostra-se o uso da fé para justificar a violência, a ganância e a intolerância, e em $O$ Evangelho segundo Jesus Cristo constrói-se um Jesus questionador, que, ao tentar ludibriar os planos de Deus, acaba precisamente caindo na trama arquitetada para ele. Essa forma de "espelho analítico" constitui-se a tônica saramaguiana e encontra em Caim um claro exemplo desse processo.
Nesse livro, que revisita episódios do Antigo Testamento, segue-se a mesma estrutura do texto bíblico, as perícopes, isto é, episódios independentes que fazem parte da cultura popular, sendo ligados por um fio condutor. No caso de Caim, há o elemento maravilhoso da presença do personagem homônimo que transita, cosendo as histórias pelo questionamento. Além dele, a própria voz narrativa não se atém a apenas descrever e apresentar, mas faz uma leitura meticulosa e comentadora da Bíblia, usando caim $^{1}$ como o porta-voz racional do que vai presenciando.

A carnavalização como fenômeno literário, conforme Mikhail Bakhtin a conceitua, é a incorporação

\footnotetext{
1 Seguindo a formatação utilizada por Saramago, os nomes de todos os personagens do romance são escritos com inicial minúscula.
} 
de elementos do carnaval no próprio fazer poético, com suas inversões da ordem hierárquica. No caso da obra saramaguiana, os temas e personagens tidos como elevados são rebaixados, assim como os marginalizados ganham destaque, encontrando-se todos num mesmo plano. Caim é eleito protagonista, por Saramago, como contraponto das histórias bíblicas, e do próprio deus.

Essa espécie de "coroação" de caim surge como representante da cosmovisão carnavalesca: "a ênfase das mudanças e transformações, da morte e da renovação. O carnaval é a festa do tempo que tudo destrói e tudo renova." (BAKHTIN, 2010, p.142). Um novo rei é instaurado, um rei que passará em revista uma série de atos do senhor, expondo-os e argumentando contra eles, forçando a que passem por uma mudança. E, como tentativa de abranger várias das passagens bíblicas, caim é lançado fora do tempo linear, surgindo nos momentos e lugares em que sua presença e suas dúvidas justificam-se.

O traço principal do realismo grotesco, elemento fundante da carnavalização, conforme Bakhtin o define, é o rebaixamento, ou seja, "a transferência ao plano material e corporal, o da terra e do corpo na sua indissolúvel unidade, de tudo que é elevado, espiritual, ideal e abstrato." (BAKHTIN, 2009, p. 17). Nesse sentido, o romance saramaguiano buscará rebaixar toda a simbologia bíblica e pô-la em contato com uma visão material. Isso se delineia desde a epígrafe do livro: "Pela fé, Abel ofereceu a Deus um sacrifício melhor do que o de Caim. Por causa da sua fé, Deus considerou-o seu amigo e aceitou com agrado as suas ofertas. E é pela fé que Abel, embora tenha morrido, ainda fala. (Hebreus, $11,4)$ LIVRO DOS DISPARATES" (SARAMAGO, 2009, p. 07). Ao colocar essa citação como epígrafe, que está nas epístolas de Paulo, e defini-la como "livro dos disparates", o autor pode se referir às próprias epístolas ou à Bíblia. Nesse último caso, podem-se analisar as três frases que compõe a citação como três enganos que se busca despir de suas vestes espirituais. Os dois irmãos ofereceram sacrifícios a deus com fé, cada um segundo sua particularidade (abel com a pecuária e caim com a agricultura, por assim dizer), mas onde estaria a noção de valor expressa? Dessa forma, não foi pela fé, mas por um capricho que deus aceitou abel e desdenhou caim. E, por fim, abel não fala, pois morreu por culpa de deus e de caim. Este último sim, fala durante todo o romance, expondo não sua fé, mas suas dúvidas constantes em torno de deus.

Retomando a história de caim e abel, segundo o narrador saramaguiano, o que se constrói são dois momentos de um diálogo de duplos. Conforme Carla Cunha apresenta, sob conceituação de Freud:
O duplo, apesar de nos parecer algo de estrangeiro, estranho a nós-mesmos, sempre nos acompanhou desde os tempos primordiais do funcionamento psíquico, estando sempre pronto a ressurgir e provocandonos uma sensação de inquietante estranheza. Nesta perspectiva, o duplo assume importante papel de mediador entre "duas entidades que não são mais que uma” (CUNHA, s/d, s/p, sublinhados nossos).

O duplo pode configurar-se segundo um de dois caminhos: o duplo homogêneo, em que o "eu" é complementado pelo duplo, mantendo-se uma harmonia entre ambos; e o duplo heterogêneo, em que o "eu" percebe as semelhanças e diferenças do duplo, estabelecendo-se um conflito devido à ameaça da perda da identidade ou à percepção da desordem provocada pela existência de ambos.

Num primeiro momento, caim e abel, ainda que contrários, compreendem que são complementares, isto é, funcionariam segundo a ideia de "duplos homogêneos". Vê-se na apresentação dos personagens essa harmonia construída: "Desde a mais tenra infância caim e abel haviam sido os melhores amigos, a um ponto tal que nem irmãos pareciam, aonde ia um, o outro ia também, e tudo faziam de comum acordo." (SARAMAGO, 2009, p.32). Mas, devido à interferência do senhor, ou antes sua preferência inexplicável pelo sacrifício de abel, caim se torna heterogêneo ao irmão. Em Caim, isso se institui não por ser ele um símbolo da inveja, mas sim por abel tornar-se símbolo da soberba:

Foi então que o verdadeiro carácter de abel veio ao de cima. Em lugar de se compadecer do desgosto do irmão e consolá-lo, escarneceu dele, e, como se isso ainda fosse pouco, desatou a enaltecer a própria pessoa, proclamando-se, perante o atónito e desconcertado caim, como um favorito do senhor, como um eleito de deus. (SARAMAGO, 2009, p. 33)

Diante do menosprezo e superioridade de abel, caim vê na presença do irmão um inimigo e por esse motivo o mata. Toda essa cena culmina no aparecimento do senhor, que passa a assumir o papel de duplo de caim. Deus aparece totalmente vestido com luxos ornamentados, de modo quase "exibicionista" para mostrar-se às suas criaturas: "Tem na cabeça a coroa tripla, a mão direita empunha o ceptro, um balandrau de rico tecido cobre-o da cabeça aos pés." (SARAMAGO, 2009, p. 34). Como um juiz, o senhor acusa caim, contudo, como a história se desenvolve em torno da figura desse último, ele adquire poder de réplica, enfrentando deus:

Mataste-o, Assim é, mas o primeiro culpado és tu, eu daria a vida pela vida dele se tu não tivesses destruído a minha, Quis pôr-te à prova, E tu quem és para pores à prova o que tu mesmo criaste, Sou o dono soberano 
de todas as coisas, E de todos os seres, dirás, mas não de mim nem da minha liberdade (SARAMAGO, 2009, p. 34)

A palavra inoportuna, conforme a ideia bakhtiniana, surge com caim questionando as provas que o senhor faz, mostrando-se sedicioso e não obediente. Caim se afirma como entidade autônoma de deus, um ser dotado de liberdade e consciência próprias. Um personagem que usa o seu discurso para enfrentar o senhor, de modo a não o deixar com a última palavra sobre o assunto, conforme se nota a acusação de deus sobre a culpa da morte de abel: "Sim, é verdade, eu fui o braço executor, mas a sentença foi ditada por ti, $\mathrm{O}$ sangue que aí está não o fiz verter eu, caim podia ter escolhido entre o mal e o bem, se escolheu o mal pagará por isso, Tão ladrão é o que vai à vinha como aquele que fica a vigiar o guarda, disse caim" (SARAMAGO, 2009, p. 35). À versão bíblica da acusação direta e unilateral de deus, vem somar-se essa possibilidade de acusação inversa, de uma culpabilidade compartilhada. Se caim é um duplo de deus, então as ações de um refletem as ação do outro. Ele matou o irmão não somente por iniciativa própria, mas sobretudo por deus o ter levado a isso, podendo ter evitado a tragédia a qualquer tempo.

Como último argumento, caim explica o seu real objetivo com o ato fratricida: "É simples, matei abel porque não podia matar-te a ti, pela intenção estás morto, Compreendo o que queres dizer, mas a morte está vedada aos deuses, Sim, embora devessem carregar com todos os crimes cometidos em seu nome ou por sua causa" (SARAMAGO, 2009, p. 35). Em Saramago, no campo da forma, os diálogos são construídos de modo que os dois lados tenham espaço para apresentar-se, sem necessariamente concluírem-se. Um retoma a ideia do outro para a complementar, dessa forma usa-se o processo de síncrise e faz-se com que a voz de caim ganhe força e equipare-se à de deus. A morte de abel foi, então, o símbolo da separação de caim com o senhor, a forma encontrada por ele de expressar o desacordo com a conduta divina. Encerrando o diálogo e tentando encontrar uma solução ao ato, deus propõe um acordo com caim, ninguém o poderá matar, mas ele deverá andar errante pelo mundo. E, por fim, deus assume responsabilidades na morte de abel, perante um surpreso caim:

Não é certo, devo estar a sonhar, Com os deuses isso acontece muitas vezes, Por serem, como se diz, inescrutáveis os vossos desígnios, perguntou caim, Essas palavras não as disse nenhum deus que eu conheça, nunca nos passaria pela cabeça dizer que os nossos desígnios são inescrutáveis, isso foi coisa inventada por homens que presumem de ser tu cá, tu lá com a divindade (SARAMAGO, 2009, p. 35-36, sublinhados nossos).
Observa-se, na declaração final, um deslocamento. Nela, o senhor é quem desmascara todos os que justificam a sua vontade pela vontade de deus, sem mais explicações. Nesse momento, deus é a contradição de si mesmo (assim como com seu desabafo com josué), revelando os que falam em seu nome como os reais inventores de verdades inamovíveis.

A partir desse primeiro diálogo, caim se tornará um personagem errante e que irá observar e analisar diferentes episódios bíblicos (alguns já apresentados na primeira parte desse artigo) com um viés paródico. Se na Bíblia deus é o rei e caim aparece como um antagonista do senhor, em Caim há a inversão de papéis, sendo que deus torna-se antagonista de caim. Dessa forma, seguindo o processo ritual da carnavalização, constituise caim como um "duplo destronante" (BAKHTIN, 2010, p. 145), isto é, um organizador para esse monde à l'envers em que o narrador o lança. Com essa ideia, pode-se pensar, conforme Bakhtin aponta em ensaio intitulado "Da Pré-história do Discurso Novelístico", sobre o discurso paródico que "a paródia desponta como uma subcategoria do potencial criativo. É o 'corretivo da realidade', sempre mais rico e mais contraditório do que qualquer gênero ou palavra singulares podem expressar." (MORSON; EMERSON, 2008, p. 452). Esse "corretivo" nada mais é do que a experimentação de uma verdade outra, contraditória, que quer mostrar a impossibilidade de uma conclusão fechada e imóvel.

Ao longo da jornada de caim pelo jogo de múltiplos presentes, ele irá tentar compreender quem é esse deus ambíguo que o marcou. Após o episódio do sacrifício de isaac, malogrado pela intervenção de caim, o anjo atrasado que deveria reter a espada de abraão despeja um recado decorado para a ocasião, por sinal o texto que se encontra na Bíblia. Caim, portador do discurso desestabilizador, rebate: "Estas, para quem não o saiba ou finja ignorá-lo, são as contabilidades duplas do senhor, disse caim, onde uma ganhou, a outra não perdeu, fora isso não compreendo como irão ser abençoados todos os povos do mundo só porque abraão obedeceu a uma ordem estúpida" (SARAMAGO, 2009, p. 81). Nas constatações e na não compreensão de caim estão os becos sem saída das histórias bíblicas, que uma argumentação racional não sustenta. Por esse motivo, também, que o anjo do senhor, diante do discurso de caim, exclama: "Mais um racionalista" (SARAMAGO, 2009, p. 81).

Para adquirir o entendimento de si, a sua autoconsciência, caim deve entender o seu duplo, isto é, deus. E como esse é um romance com uma atmosfera carnavalesca, que significa "lugar santo assassinado", segundo a etimologia alemã, caim construirá um mosaico dos atos de deus para compreendê-lo. Depois da cena de abraão e isaac, caim se vê diante da torre de babel, local em que 
verá mais um modo de matar a deus, figurativamente. A partir da confusão linguística, caim contextualiza-se e percebe a situação dos homens em relação a deus:

Decidimos construir uma cidade com uma grande torre, essa que aí está, uma torre que chegasse ao céu, Para quê, perguntou caim, Para ficarmos famosos, E o que aconteceu, por que está a construção parada, Porque o senhor veio vê-la e não gostou, Chegar ao céu é o desejo de todo o homem justo, o senhor até deveria dar uma ajuda à obra, Era bom, era, mas não foi assim, Então que fez ele, Disse que depois de nos termos posto a fazer a torre ninguém mais nos poderia impedir de fazer o que quiséssemos, por isso confundiu-nos as línguas e a partir daí, como vês, deixámos de entender-nos (SARAMAGO, 2009, p. 85-86, sublinhados nossos).

O narrador, a partir da voz de caim, apropria-se do discurso religioso, da busca do homem justo para chegar ao céu, e o insere num contexto em que os que tentaram tal ação foram castigados por deus, evidenciando a contradição, presente também na própria Bíblia (cf. Gn 11:1-9). O jogo de oxímoros, como elemento da sátira menipeia, vai aqui ganhando força, pois mostra-se um deus ciumento dos homens. Caim expõe essa definição sobre deus em sua conclusão sobre a história da torre: "O ciúme é o seu grande defeito, em vez de ficar orgulhoso dos filhos que tem, preferiu dar voz à inveja, está claro que o senhor não suporta ver uma pessoa feliz" (SARAMAGO, 2009 , p. 86). O livro vai se desenvolvendo seguindo essa dinâmica: apresenta-se o texto bíblico, atualizando a linguagem, mas não seu conteúdo, e caim (o narrador) se encarrega de apresentar um juízo sobre o que se viu. No caso da torre, a "palavra inoportuna" da inveja do senhor funciona como uma característica constante do estilo do realismo grotesco, que tem como base atacar o discurso especular. "Sua força transgressora é mais intensa quando o discurso que deve se refletir no espelho já exibe aspectos da degeneração a que é submetida a linguagem cada vez que é utilizada para construir enunciados cuja estrutura obedece a formas consagradas pelo uso" (CAÑIZAL, in: BRAIT, 2010, p. 250). Vê-se, então, a força que Caim adquire, pois irá contra o senso comum das histórias bíblicas. Ao discurso lacunar da Bíblia, Saramago insere uma voz contrária, carnavalizada, que força uma leitura próxima e direta daquilo que muitos sabem por "ouvir contar". Dessa forma, além de um deus exibicionista, ambíguo e invejoso, caim se depara com mais um epíteto aplicável ao senhor quando se vê diante do ataque a sodoma: um deus injusto.

Na história bíblica, deus conta a abraão que destruirá a cidade de sodoma e os arredores por terem cometido pecados graves. Abraão pede pelos inocentes da cidade e deus lhe faz uma promessa. Ao final, sodoma é devastada pela justiça divina. Em Caim, o que se conclui desse episódio é que o senhor é injusto. Mais uma vez, o protagonista foi transportado de modo a presenciar a cena, acompanhando abraão em sua conversa com deus. Resgatando o discurso bíblico, surgem os questionamentos de abraão ao senhor:

Será que vais destruir os inocentes juntamente com os culpados, vamos supor que existem uns cinquenta inocentes em sodoma, vais destruí-los também a eles, não serás capaz de perdoar a toda a cidade em atenção aos cinquenta que se encontram inocentes do mal. (...) Não é possível que vás fazer uma coisa dessas, senhor, condenar à morte o inocente juntamente com o culpado, desse modo, aos olhos de toda a gente, ser inocente ou culpado seria a mesma coisa, ora, tu, que és o juiz do mundo inteiro, deves ser justo nas tuas sentenças (SARAMAGO, 2009, p. 92-93).

Diante de tão incisivas perguntas, que louvam e tentam dissuadir, o senhor mostra-se magnânimo e diz que, se houver inocentes (dez, após o jogo dialético de abraão com deus), todos serão poupados. Isso basta para acalmar os ânimos de abraão, mas não de caim, que funciona como um instigador das ideias. Caim pergunta a abraão:

Como te parece que vai o senhor contar os dez inocentes que, no caso de existirem, evitariam a destruição de sodoma, crês que irá de porta em porta inquirindo das tendências e dos apetites sexuais dos pais de família e seus descendentes machos, O senhor não precisa fazer escrutínios desses, ele só tem de olhar a cidade lá de cima para saber o que nela se passa, respondeu abraão, Queres tu dizer que o senhor fez aquele acordo contigo para nada, só para te comprazer, tornou caim a perguntar (SARAMAGO, 2009, p. 94).

Caim utiliza-se, então, do método maiêutico para extrair uma verdade de abraão a partir da própria fala dele. O exemplo absurdo de deus bater de porta em porta é rebatido pela onipresença divina, e esse elemento contradiz a ideia inicial do senhor não saber se haveria inocentes em sodoma. É por esse motivo que caim, com uma pergunta retórica, mostra que o acordo feito foi apenas para que abraão se calasse.

Logicamente que caim é um porta-voz atuante da voz narrativa, igualmente crítica e irônica das ações do senhor. Isso é algo que se vai construindo no personagem desde sua descoberta da preferência de deus por abel e da análise dos acordos feitos com caim, abraão, josué. Por esse motivo, quando caim preconiza que sodoma será destruída, independente dos inocentes, é porque ele já conhece o modus operandi do senhor. Como efeito 
dramático, ele aguarda até o castigo ser concretizado, e dirige-se a abraão, seu interlocutor:

Tenho um pensamento que não me larga, Que pensamento, perguntou abraão, Penso que havia inocentes em sodoma e nas outras cidades que foram queimadas, Se os houvesse, o senhor teria cumprido a sua promessa que me fez de lhes poupar a vida, As crianças, disse caim, aquelas crianças estavam inocentes, Meu deus, murmurou abraão e a sua voz foi como um gemido, Sim, será o teu deus, mas não foi o delas (SARAMAGO, 2009, p. 97).

A morte das crianças inocentes é um tema que Saramago recorre, também, em $O$ Evangelho segundo Jesus Cristo, motivo principal da culpa de José e herança da culpa para Jesus. Em Caim, a culpa de deus pela morte das crianças de sodoma será continuamente lembrada, como uma chaga não curada. Além disso, no diálogo, o argumento de abraão é suprimido perante a prova apresentada por caim, e a exclamação final mostra, precisamente, a duplicidade do senhor, o deus de abraão não pode ser o mesmo deus das crianças mortas.

Caim é o duplo paródico de deus, pois enquanto o senhor seria aquele que tudo sabe, aquele que todos buscam, ele é o que questiona, busca, para compreender. Caim trabalha com a palavra, sobretudo as palavras dos outros (discurso bíblico), para remexê-las e descobrir um sentido não automatizado. Conforme Bakhtin observa, "as palavras paródicas que usamos são importantes não porque podem mudar a realidade (não precisam disso), mas porque aumentam a nossa liberdade com respeito à escolha interpretativa, ao fornecer-nos novas perspectivas." (MORSON; EMERSON, 2008, p.453). Se Caim é uma versão paródica da Bíblia, é por meio das palavras enfrentadoras que isso se realiza, a partir do embate com o texto original e da exibição das suas lacunas e contradições inerentes. A carnavalização de Caim nada mais é do que uma exposição em praça pública daquilo que não mais se percebe, graças ao véu do senso comum.

Dois exemplos complementares podem ser trazidos para a constituição do personagem caim como contraponto de deus. O primeiro acontece no monte sinai, no episódio do bezerro de ouro. Quando moisés vê o seu povo adorando um bezerro de ouro, destrói-o e mostra a ira de deus em seu mais alto nível:

Então todos os levitas se reuniram em volta de Moisés e ele disse:

- O Senhor, o Deus do povo de Israel, manda que cada um de vocês pegue a sua espada e vá pelo acampamento, de ponta a ponta, matando os seus parentes, os seus amigos e os seus vizinhos.
Os levitas obedeceram à ordem de Moisés e mataram naquele dia mais ou menos três mil homens. Moisés disse aos levitas:

- Hoje vocês mataram os seus filhos e os seus irmãos e assim se consagraram como sacerdotes para o serviço de Deus, o Senhor. E, porque vocês fizeram isso, Deus lhes deu hoje uma bênção (ÊXODO, 32, p. 26-29).

O mesmo discurso é apresentado pelo narrador em Caim, com a descrição mais pormenorizada e crua dos assassinatos dos homens. Para além disso, caim vê a cena e tece o seu comentário:

Não bastavam sodoma e gomorra arrasadas pelo fogo, aqui, no sopé do monte sinai, ficara patente a prova irrefutável da profunda maldade do senhor, três mil homens mortos só porque ele tinha ficado irritado com a invenção de um suposto rival em figura de bezerro, Eu não fiz mais que matar um irmão e o senhor castigou-me, quero ver agora quem vai castigar o senhor por essas mortes, pensou caim (SARAMAGO, 2009, p. 101).

A todo o rol de adjetivos contraditórios dados ao senhor, caim acrescenta o de mau. E aproveitando de seu papel de igualdade com deus, caim o quer chamar à justiça, ao castigo devido àquele que tantas pessoas mandou à morte. E, como complemento a essa maldade, o narrador lança mão do segundo exemplo selecionado, da vingança do exército de israel aos madianitas (cf. NÚMEROS, 31: 1-54). Após a batalha e morte dos inimigos, algo que não mais surpreendia caim, houve a separação dos despojos, quando o senhor dá as ordens e faz as contas quanto aos tributos devidos a ele. Nesse momento, o narrador fala: "Como fica sobremaneira demonstrado, o senhor, além de estar dotado por natureza de uma excelente cabeça para guarda-livros e ser rapidíssimo em cálculo mental, está o que se chama rico." (SARAMAGO, 2009, p. 107). Essas qualidades conferem caráter mundano e material a deus, um ser, por definição, espiritual. E caim surge com uma conclusão a se concretizar sobre a relação do senhor com as batalhas:

Caim pensou, Está visto que a guerra é um negócio de primeira ordem, talvez seja mesmo o melhor de todos a julgar pela facilidade com que se adquirem do pé para a mão milhares e milhares de bois, ovelhas, burros e mulheres solteiras, a este senhor terá de chamar-se um dia deus dos exércitos, não lhe vejo outra utilidade, pensou caim, e não se enganava (SARAMAGO, 2009, p. 107).

A propensão do senhor para a guerra é taxada por caim como a causa e o destino de desse deus. Antecipando a expressão que os Salmos confeririam ao senhor, 
"deus dos exércitos", o personagem lhe dá uma nova perspectiva, rebaixada e negativa, que o narrador finaliza confirmando. Sobre a voz que narra, inclusive, observa-se sua transição entre o tempo bíblico e o tempo futuro, além de um vocabulário ambivalente, típico da carnavalização. Segundo Bakhtin, "O vocabulário da praça pública é um Jano de duplo rosto. (...) [Ele] estava orientado para o mundo e para cada fenômeno desse mundo em estado de perpétua metamorfose, de passagem de noite a dia, de inverno a primavera, do velho ao novo, da morte ao nascimento." (BAKHTIN, 2009, p. 142). Do religioso ao científico (como a rotação terrestre em josué ou a lei do empuxo em noé), das profecias às falas turísticas (como a referência ao guia michelin para caim (SARAMAGO, 2009, p. 146)), o discurso saramaguiano de Caim se pauta pela contínua profanação do texto bíblico, não no sentido de negá-lo veementemente, mas sim como o enfrentamento típico da paródia. "O próprio riso carnavalesco é profundamente ambivalente. (...) Este estava voltado para o supremo: achincalhava-se, ridicularizava-se o Sol (deus supremo), outros deuses, o poder supremo da Terra para forçá-los a renovar-se." (BAKHTIN, 2010, p. 144). Bakhtin salienta a busca que a palavra e o conteúdo paródicos empreendem para revolver o discurso solidificado, e Saramago, em Caim, explicitamente fará essa experimentação de renovar a interpretação bíblica.

Como síntese prévia, após todas essas visitas por episódios emblemáticos da relação do senhor com os homens, e dos desentendimentos oriundos dela, caim se vê novamente na terra de nod, lugar onde reside lilith. Essa personagem representa o arquétipo de femme fatale e, dentro da tradição hebraica, pode ser considerada ora a primeira mulher de adão, ora a segunda, ou ainda como o real motivo da briga de caim e abel (FRYE, 2004, p. 174). De toda maneira, ela simboliza a mulher dominadora, não submissa, e por esse motivo, por contrariar a mentalidade bíblica, Saramago a elege como rainha da terra de nod e mulher de caim. Se no primeiro encontro entre os dois, caim era o "prisioneiro" carnal de lilith, após toda a sua errância já possui mais consciência de si ou, pelo menos, de deus. Nesse segundo encontro, caim está mais amadurecido e dialoga com lilith para tentar digerir as ações do senhor e como ele se encaixaria nesse mundo:

Não sei se fui escolhido, mas algo sei, sim, algo devo ter aprendido, Quê, Que o nosso deus, o criador do céu e da terra, está rematadamente louco, Como te atreves a dizer que o senhor deus está louco, Porque só um louco sem consciência dos seus atos admitiria ser o culpado direto da morte de centenas de milhares de pessoas e comportar-se depois como se nada tivesse acontecido, salvo, afinal, que não se trate de loucura, a involuntária, a autêntica, mas de pura e simples maldade (SARAMAGO, 2009, p. 128-129).
Dessa forma, caim consegue chegar a um ponto de vista com relação a deus. A partir de seu primeiro diálogo com o senhor, teve contato com outras consciências, todas subservientes do senhor, e enfrentou-as, embutindo nelas dúvidas suas. Como epíteto final, define que deus é louco ou mau, e de qualquer maneira responsável pela morte de milhões, e percebe que talvez acabe tendo de ir ao encontro dele uma vez mais. Não caberia a caim mudar os fatos, mas ele seria o representante do poder contemplativo "da testemunha e do juiz" (MORSON; EMERSON, 2008, p. 453), seria aquele que vê e constrói sentidos, seria aquele que julga deus.

O encontro se dá no episódio da arca de noé, em que deus surpreende-se com a presença de caim, e este lhe esclarece o que andou vendo e fazendo. E se no primeiro momento caim já contava com alguma proximidade com o senhor, do ponto de vista dialético, nesse ele sente-se mais apto para enfrentar a deus, por contar com argumentos e provas. O senhor, por seu lado, permanece com certo ar bufão, megalômano, dos primeiros tempos do jardim do éden, como se expressa na frase: "sou dotado de uma consciência tão flexível que sempre a encontro de acordo com o que quer que faça" (SARAMAGO, 2009, p. 149). Retomando a história de job, da qual caim partira antes do final, o senhor lhe atualiza, dizendo de como ele, com seu poder absoluto, dobrou todos os bens de job. Quanto aos filhos que morreram, deus os considera um pormenor sem importância e conclui: "terá outros dez filhos, sete varões e três fêmeas como antes, para substituir os que perdeu, Da mesma maneira que os rebanhos, Sim, da mesma maneira que os rebanhos, os filhos não são mais que isso, rebanhos." (idem, ibidem) A declaração, se se levar em conta a história de isaac ou de Jesus, adquire um sentido de sacrifício feito para agradar ao senhor, não havendo espaço para qualquer ligação emotiva.

Com isso, lembrando-se do lugar em que estava e do papel que deveria desempenhar, o senhor explica a razão de ser da construção da arca, "como se repetisse um discurso já feito antes e decorado" (idem, p. 151), e caim rebate discutindo os princípios físicos envolvidos e a impossibilidade de tal ato. Na continuação do diálogo, caim torna a falar de job,

que não ousou amaldiçoar-te, mas que leva no coração toda a amargura do mundo, Que sabes tu do coração de job, Nada, mas sei tudo do meu e alguma coisa do teu, respondeu caim, Não creio, os deuses são como poços sem fundo, se te debruçares neles nem mesmo a tua imagem conseguirás ver, Com o tempo todos os poços acabam por secar, a tua hora também há-de chegar (SARAMAGO, 2009, p. 153).

Ao dizer o que há nos corações, caim refere-se também à consciência que move esses personagens, sabendo 
somente como ele próprio se constitui, pois encontra-se definido em relação ao seu duplo, de quem descobriu parte da consciência do senhor a partir das suas atitudes. Após a declaração do coração de deus secar-se como um poço, o senhor desvirtua o assunto, lembrando do sinal na testa de caim: "parece um sol negro a levantar-se do horizonte dos olhos, Bravo, exclamou caim batendo palmas, não sabia que eras dado à poesia, É o que eu digo, não sabes nada de mim." (ibidem). Essa magoada declaração do senhor é o fim do segundo diálogo, marcando um lado humano de deus, apesar da contradição, pautado pela solidão que cerca tal ser. Nesse momento único no livro todo, deus se revela como um personagem triste, que apesar de ter seus fiéis e seus anjos, não possui ninguém com quem conversar igualitariamente, nem mesmo caim, por ser ele um duplo heterogêneo.

Somando-se essa face de deus às demais presentes em Caim, retoma-se o conceito bakhtiniano da paródia, que "mina não a autoridade em princípio, mas apenas a autoridade com pretensões a ser atemporal e absoluta." (MORSON; EMERSON, 2008, p.453). Deus, apesar de ser o criador, pode falhar, pode demonstrar maldade, arrogância, maus julgamentos e certa dose de loucura, de modo que a autoridade dele não é total nem irrestrita, mas sim precisa ser discutida continuamente, numa constante complementação.

Após o dilúvio, quando deus chama por noé e ele não aparece, surge caim para o terceiro e último diálogo. Noé e os seus estão mortos, caim os matara a todos, e comunica isso perante um surpreso deus: "Como te atreveste, assassino, a contrariar o meu projecto, é assim que me agradeces ter-te poupado a vida quando mataste abel, perguntou o senhor, Teria de chegar o dia em que alguém te colocaria perante a tua verdadeira face" (SARAMAGO, 2009, p. 172, sublinhados nossos). O livro Caim, em sua cosmovisão carnavalesca e composição paródica, pode ser resumido na frase em destaque. É nela que reside todo o processo de destronamento de deus e elevação de caim, tornando-se um o espelho do outro, caim como revelador de deus. O projeto do senhor para a humanidade (lembrando que adão e eva foram um experimento) finda-se com a morte de noé, sendo que caim foi o responsável por essa interrupção. Diante da perda de seu poder pelo término da sua criação, o senhor se sente acuado: "Então a nova humanidade que eu tinha anunciado, Houve uma, não haverá outra e ninguém dará pela falta, Caim és, e malvado, infame matador do teu próprio irmão, Não tão malvado e infame como tu, lembra-te das crianças de sodoma." (SARAMAGO, 2009, p. 172). Caim mostra-se superior a deus, pois mantém sua segurança perante a desestabilização de seu duplo. Mesmo na troca de ofensas, caim se equipara ao senhor, ambos maus e assassinos.
O livro termina com a inconclusibilidade do discurso de ambos, opositores entre si: "A resposta de deus não chegou a ser ouvida, também a fala seguinte de caim se perdeu, o mais natural é que tenham argumentado um contra o outro uma vez e muitas, a única coisa que se sabe de ciência certa é que continuaram a discutir e a discutir estão ainda." (SARAMAGO, 2009, p. 172). O narrador não é o detentor da última palavra sobre os personagens, nem mesmo eles próprios, pois um complementa o outro. $\mathrm{Na}$ verdade, a simbologia de caim e do senhor é a dos dois lados antagônicos postos em conflito, no eterno inacabamento da existência.

Com isso, o fenômeno da carnavalização, em Saramago, se constitui pela quebra hierárquica total, tornando igualitários os personagens e o narrador orquestrando a todos. Em Caim, particularmente, há a profanação carnavalesca como base fundadora, uma vez que o narrador vê o senhor como um antagonista: "A história dos homens é a história dos seus desentendimentos com deus, nem ele nos entende a nós, nem nós o entendemos a ele." (SARAMAGO, 2009, p. 88). É essa a verdade que o autor experimenta, a verdade dos desentendimentos com deus, exemplificada com caim, por ser o primeiro antagonista direto de deus.

Pode-se notar que as definições não são algo hermético, deus não é totalmente bom, pois pede mortes, caim não é totalmente mau, pois salvou isaac. Na verdade, como exemplo do jogo de oxímoros sobre o qual se montam as peças do livro, ambos são, ao mesmo tempo, vítima e algoz um do outro. O senhor deu o castigo a caim pela morte de abel, mas antes disso, tinha lhe desdenhado e cortado sua fé. Caim, como represália, tenta entender a deus e lhe dá o castigo de destruir os planos que tinha para uma humanidade criada. Lilith declararia, quando do regresso de caim: "Ninguém é uma só pessoa" (SARAMAGO, 2009, p. 126), assim sendo, o livro de José Saramago busca a razão para metamorfosear a fé, procura o confronto de ideias para solidificar os argumentos. Ao declarar na imprensa que "a Bíblia é um manual de maus costumes", José Saramago não quer apenas provocar, mas sim buscar a renovação da fé a partir do escárnio que espera uma resposta.

\section{Referências}

BAKHTIN, Mikhail. A cultura popular na Idade Média e no Renascimento: o contexto de François Rabelais. Tradução Yara Frateschi Vieira. São Paulo: Hucitec; Brasília: Editora Universidade de Brasília, 2009.

Problemas da poética de Dostoiévski. Tradução Paulo Bezerra. Rio de Janeiro: Forense Universitária, 2010.

ÊXODO. In: BÍBLIA Sagrada. Barueri: Sociedade Bíblica do Brasil, 2000. Cap 32, vers. 26-29, p. 94. 
BRAIT, Beth (Org.) Bakhtin: outros conceitos-chave. São Paulo: Contexto, 2010.

CUNHA, Carla. O duplo. In: CEIA, Carlos. E-Dicionário de Termos Literários. Disponível em: <http://edtl.fcsh.unl.pt/ encyclopedia/duplo/>. Acesso em: 26 maio 2018.

FRYE, Northrop. Código dos códigos: a Bíblia e a literatura. Tradução Flávio Aguiar. São Paulo: Boitempo, 2004.

MORSON, Gary Saul; EMERSON, Caryl. Mikhail Bakhtin: criação de uma prosaística. Tradução Antonio de Pádua Danesi. São Paulo: Editora da Universidade de São Paulo, 2008.
SARAMAGO, José. Caim. São Paulo: Companhia das Letras, 2009.

Recebido: $27 / 05 / 2018$

Aprovado: 24/01/2019

Autor:

SAULO GOMES THIMÓTEO

Doutorando. Universidade Federal da Fronteira Sul (UFFS).

sthimoteo@gmail.com 